\title{
Disproportionate Burden of HIV Prevalence among Men and Women assessing HIV Testing and Counseling Services in Cross River State, Nigeria.
}

\author{
N. C. Osuchukwu', A. A. Onovo ${ }^{2}$, A. O. Atobatele ${ }^{3}$, I. E. $\mathrm{Nta}^{2}$ \\ ${ }^{1}$ University of Calabar, Cross River, ${ }^{2}$ Institute of Human Virology, Nigeria (IHVN), ${ }^{3}$ United States Agency for \\ International Development, Nigeria (USAID-Nigeria).
}

\begin{abstract}
Background: In Sub-Saharan Africa, approximately 57\% of Adults living with HIV are Women.HIV prevalence in Cross River State is $7.1 \%$, compared to National of $4.1 \%$. This study aims to ascertain the HIV prevalence rates among men and women assessing HIV Testing and Counseling (HTC) services in Nigeria's South-South region. Methods: Cross-Sectional quantitative study was conducted in November, 2011 among clients who received HTC services in 34 Primary Health centers across 5 LGAs of Cross River state. Relevant data of HIV Sero-Status of clients were collected from provider administered HTC client intake forms. Data was analyzed using Pearson Chi-Square. Results: 690 clients 316 (45.8\%) male and 374 (54.2\%) females were tested for HIV using Determine Abbott test kits. Age distribution of clients ranged from 18-41 years with mean age of 29.5 years. Prevalence of HIV among clients is 4.2\% (29/690) with women contributing 7.0\% (25/374) as compared with Men 1.2\% (4/316). There was a significant association between HIV Sero-Status of Men and Women, (Pearson Chi-Square, $P=0.01$ ). Conclusion: This result indicates that HIV Prevalence among women is disproportionately greater than that among men in Cross River state which appeared significant at the 95\% confidence interval.
\end{abstract}

Key words: HIV Sero-prevalence, HIV test kits,HIV Testing and Counseling (HTC), Key population, Prevention of Mother-to-Child Transmission (PMTCT).

\section{Introduction}

The HIV/AIDS pandemic is one of the most serious health crises the world is facing today. A disproportionate burden has been placed on women and children, who in many settings continue to experience high rates of new HIV infections and of HIV - related illness and death (FMOH, 2010) ${ }^{[5]}$. Of the 17 million new infections among women in 2005, 13.5 million were in sub-Saharan Africa (almost 80\%), and well over half (57\%) of adults 15- 49 living with HIV in sub-Saharan Africa are women.

In 2009, 33.3 million individuals were living with HIV, of whom 15.7 million were women and 2.1 million were children under 15 years of age $(\mathrm{FMOH}, 2010)^{[5]}$. Globally, HIV is the leading cause of death in women of reproductive age (UNAIDS, 2011) ${ }^{[16]}$.

The emergence of HIV/AIDS in sub-Saharan Africa over two and half decades ago presented a devastating health crisis to millions of people in the continent. Over 24.5 million people were estimated to be living with the disease at the end of 2005 (UNAIDS, 2006) ${ }^{[17]}$ which represents about $65 \%$ of the global figure. Also an estimated 2.7 million people were newly infected and 2.5 million adults and child deaths occurred due to AIDS in the region during 2005 (UNAIDS 2006).

Nigeria carries the second heaviest burden of HIV in Africa and has an expanding population of People Living with HIV (PLHIV). Despite challenges in scaling up access, institutional reforms and political commitment to tackle the diseases, the country has seen more citizens placed on life saving medication. For the 26 year period from 1986 till December 2011, when the first HIV case was reported in Nigeria, 217,148 people have died from AIDS (FMOH, 2010) ${ }^{[5]}$. 3,459,363 people are living with HIV.

Nigeria witnessed an increase in the prevalence of HIV in the country between 1991 and 2001. The national HIV Sero-prevalence level, obtained from sentinel surveys of antenatal care attendees, increased from 1.8 percent in 1991 to 5.8 percent in 2001 and then declined to 5.0 percent in 2003 and further to 4.4 percent in 2005. This was followed by a rise to 4.6 percent in 2008 and then a recent decline to 4.1 percent in 2010 $(\mathrm{FMOH}, 2010)^{[5]}$. Although the national median prevalence of HIV has dropped in recent years, however the absolute number of people living with HIV has increased by almost half a million people in three years and AIDS related mortality has also slightly increased in the same time period to about 217,148 annual deaths attributed to AIDS (UNAIDS, 2008) ${ }^{[18]}$.

In Nigeria, $80 \%$ transmission of HIV is predominantly heterosexual but Mother-To-Child Transmission (MTCT) is also significant and accounts for 10\% transmission of HIV infection. Key drivers of the HIV epidemic in Nigeria include low personal risk perception, multipleconcurrent sexual partnerships, intense 
transactional and inter-generational sex, ineffectiveand inefficient services for sexually transmitted infections (STIs), and inadequate access toand poor quality of healthcare services. Entrenched gender inequalities and inequities,chronic and debilitating poverty, and stubborn persistence of HIV/AIDS-related stigma anddiscrimination also significantly contribute to the continuing spread of the infection.

With no available cure for HIV/AIDS, Antiretroviral therapy (ART) provides the only viable remedy to manage and reduce the health crises posed by the infection in sub-Sahara Africa. Several efforts have been made to control and conquer the disease but there is no cure yet, neither is there an effective vaccine to prevent HIV infection because of the persistently changing nature of the virus (Odutolu et al., 2006; WHO et al., 2010) ${ }^{[12][15]}$ The two main strategies currently adopted for combating this epidemic are preventing new HIV infections and providing antiretroviral drugs for those already infected. Both can only be achieved when people are aware of their HIV status through the HIV Testing and Counseling (HTC) process (UNAIDS and WHO, 2010) ${ }^{[15]}$.

HTC is a confidential process during which an individual or a couple is counseled and encouraged to assess their risk of acquiring or transmitting the virus. It can lead to testing, but the individuals can decide to weigh the options before requesting to be tested (UNAIDS, 2000). HTC has several benefits which have been documented (Boswell and Baggaley, 2002) ${ }^{[1]}$.

HTC was initially restricted to hospital settings in which people presenting with symptoms and signs suggestive of HIV/AIDS were tested to confirm the diagnosis.Before the advent of rapid test kits, HIV tests were performed in specialized laboratories and confirmed by the Western Blot test. Those tested had to wait for two days to two weeks in anxiety and anticipation of what the results might be, while others never came back for their results (Kipp et al., 2002; Paul et al., 2004) ${ }^{[7][13]}$.

The advent of rapid kits whereby people can obtain their test results almost immediately and which has made HTC to be available at sites other than the hospital settings, has encouraged more people to test. Moreover, the fact that HIV has become a treatable condition has caused a major change in attitudes towards testing (Turner-Stokes, 2005) ${ }^{[14]}$.

In spite of these facts, however, majority of the people in Nigeria are not aware of their HIV status. The 2005 National HIV/AIDS and Reproductive Health Survey (NARHS) reported an overall uptake of 11 and 10\% for men and women respectively (FMOH, 2010) ${ }^{[5]}$.

Cross River in Nigeria, ranks $3^{\text {rd }}$ highest rate of HIV prevalence As compared with other states in the South-South zone of Nigeria. The HIV prevalence among states in the South-South zone of Nigeria is 6.5\%. Cross River State has HIV prevalence of 7.1\%, compared with National HIV Prevalence of $4.1 \%$ (as per HSS $2010)^{[8]}$. This community based study ascertained the disproportionate burden of HIV Prevalence among Men and Women assessing HIV Testing and Counseling Services in Cross River State located in the South-South part of Nigeria.

\subsection{Study location}

\section{Materials And Methods}

The study location was Cross River State. The state is located in the South-South Geo-Political Zone of Nigeria. It shares boundary with Akwa Ibom, Abia, Ebonyi and Benue State and international boundary with the Republic of Cameroon. The state capital is Calabar. The state is divided into three political senatorial districts namely Southern, Northern and Central Cross River and consists of 18 Local Government Areas (LGAs). The state has many centres of attraction, prominent among which are the Obudu Cattle Ranch and Tinapa Resort. The State is known as the People's Paradise. With reference to the 2006 Population and Housing Census, Cross River state is made up of 1,471,967 males and 1,421,021 females. The State is composed of three major ethnic groups: the Efik, the Ejagham, and the Bekwarra. The Efik language is widely spoken in Cross River state and as far as Arochukwu in neighboring Abia state. The Cross River State economy is predominantly agricultural and is sub-divided into two sectors - the public and the private sectors. The private sector is dominated by local subsistence farmers while the public sector is run by the Government and features large plantations and demonstration farms. The main crops produced are cassava, yams, rice, plantain, banana, cocoyam, maize, cocoa, rubber, groundnut and palm produce. The state boasts of being the venue for the largest carnival in Africa.

\subsection{Study design}

The study employed a Cross-sectional quantitative design.

\subsection{Sampling technique}

The study was conducted in November, 2011 among clients who received HTC services in 34 Primary Health Care centers spread across 5 LGAs in Cross River state namely; Calabar South, Calabar Municipal, Odukpani, Yakurr, and Akpabuyo respectively. The 5 LGA's were selected using stratified random sampling. A total of Six hundred and Ninety (690) clients were tested for HIV by trained health care nurses and community 
based HTC volunteers from the 34 Primary Health Care facilities using Systematic random sampling. The inclusion criterion was adults of reproductive age (males aged 15 to 59 years old and females aged 15 to 49 years old).

\subsection{Data Collection}

Relevant data of the HIV Sero-Status of the clients were collected from provider administered HTC client intake forms. The client intake forms elicited information about respondents' previous uptake of HTC, demographic information, HIV education, HIV risk assessment, syndrome STI screening, clinical TB screening and HIV test result. Permission to carry out the research was obtained from the Primary Health Care Directors of the LGAs in which the study was conducted. Informed consent wasobtained from the clients prior to data collection.

\subsection{Data Analysis}

Data generated were analyzed using the Statistical Package for Social Sciences version 20.0 (IBM,SPSS 20.0). Descriptive statistics were used to present clients' demographic variables and uptake of HTC while Pearson Chi-Square was used to present the relationship between some socio-demographic variables and HTC uptake. A p value $\leq 0.05$ was considered statistically significant.

\section{Results}

A total of 690 clients were tested for HIV using Determine Abbott HIV test kits. These consisted of $316(45.8 \%)$ male and $374(54.2 \%)$ females. The age distribution of the clients ranged from 18-41 years with the mean age of 29.5 years.

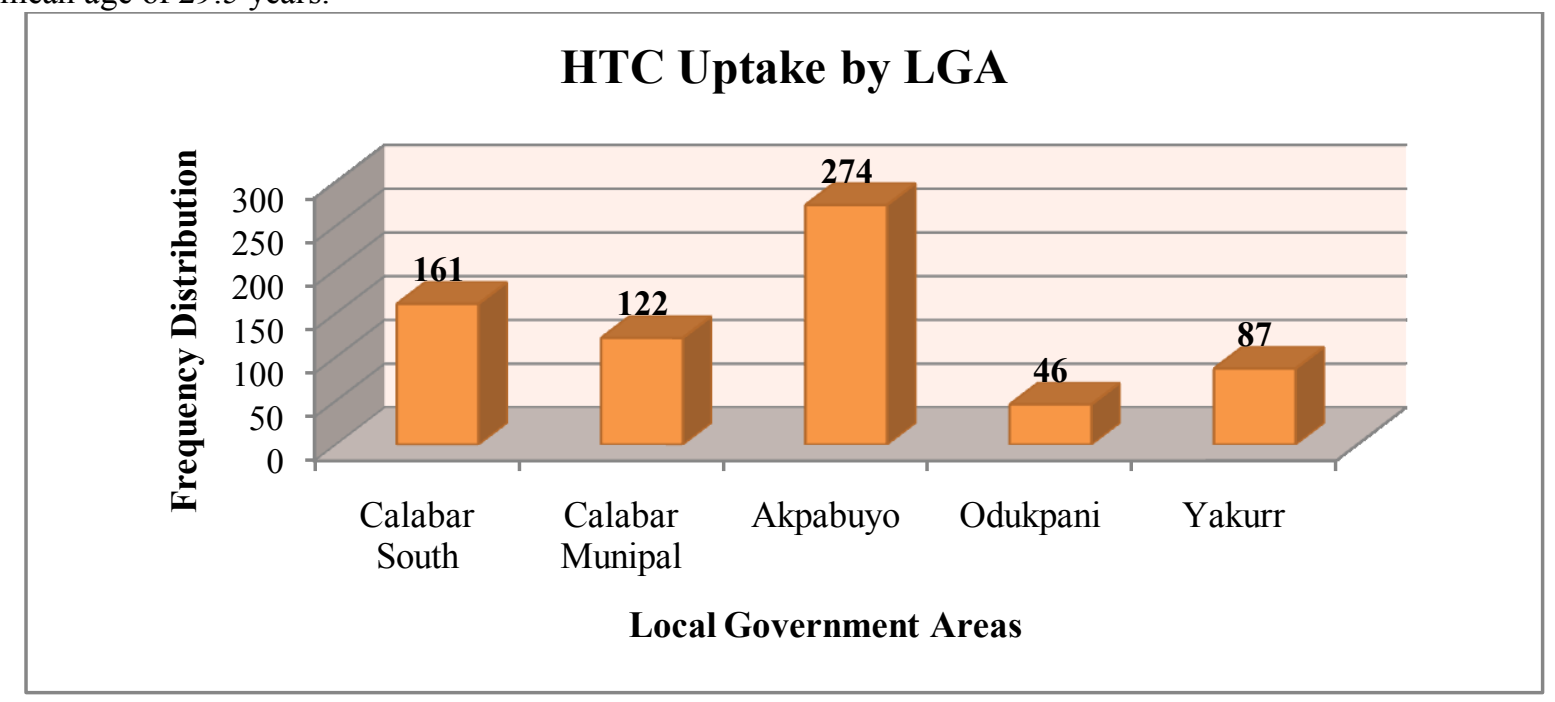

Figure 1: Distribution of the uptake of HTC services among study clients by LGAs in Cross River state.

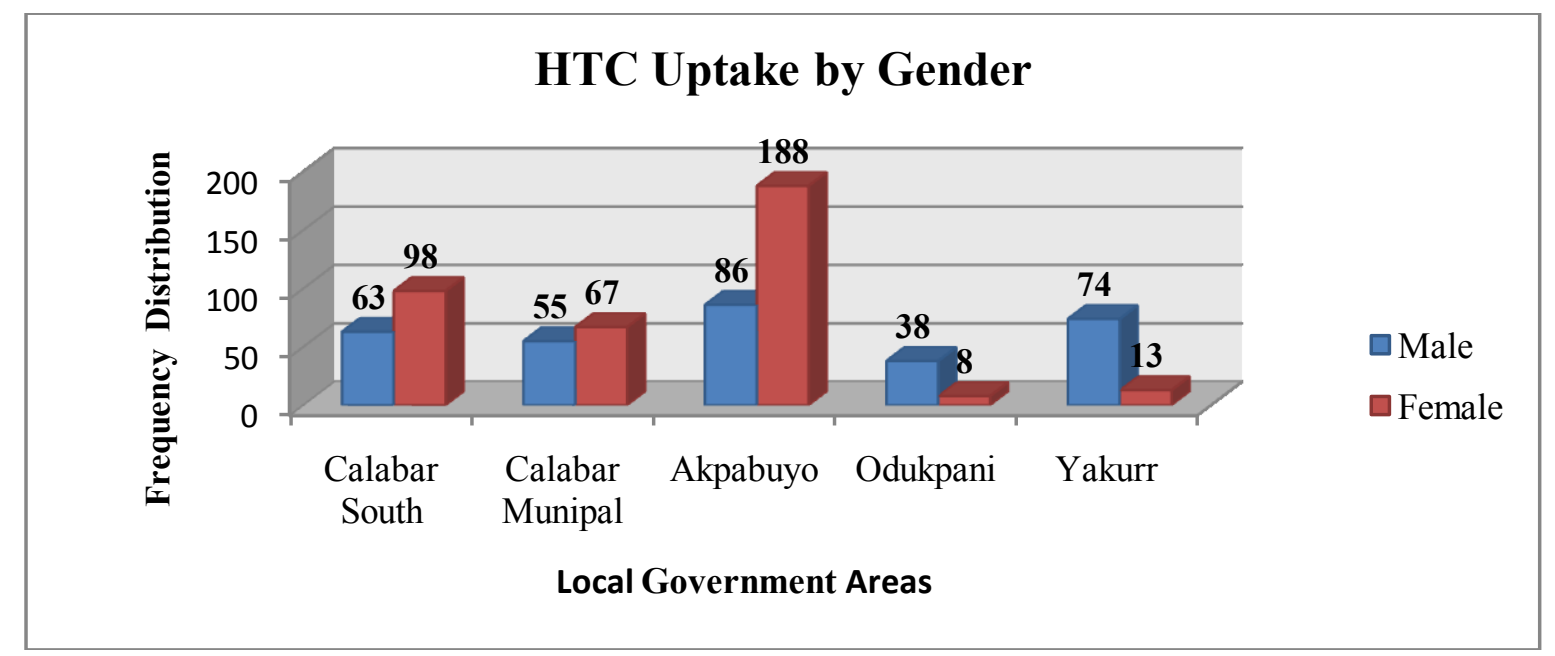

Figure 2: Distribution of the uptake of HTC services among clients by Gender in 5 LGAs of Cross River state. 


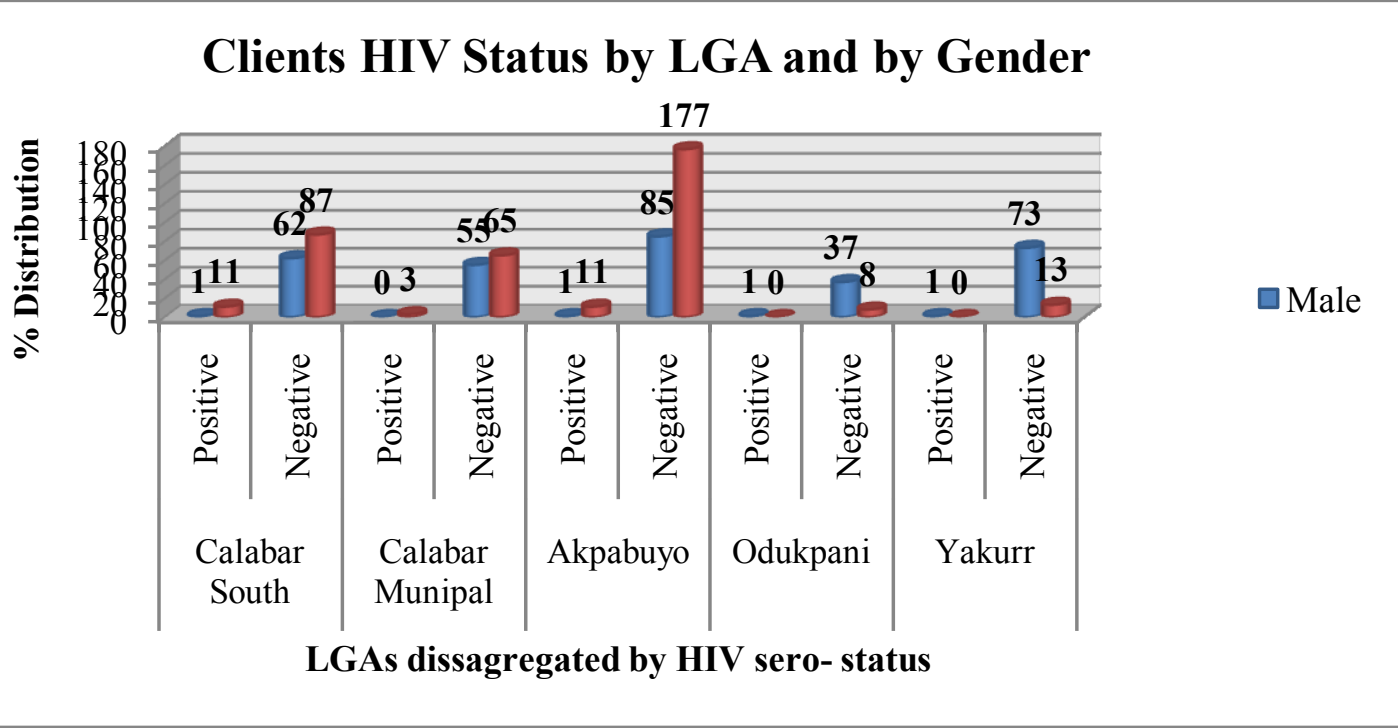

Figure 3: Distribution of HIV status among clients tested and counseled by LGAs and by Gender.

The Prevalence of HIV among the clients is $4.2 \%$ (29/690). Prevalence of HIV among Women is $7.0 \%$ (25/374) as compared with Men 1.2\% (4/316). There was a significant association between the HIV Sero-Status of Men and Women, (Pearson Chi-Square, $\mathrm{P}=0.01$ ).

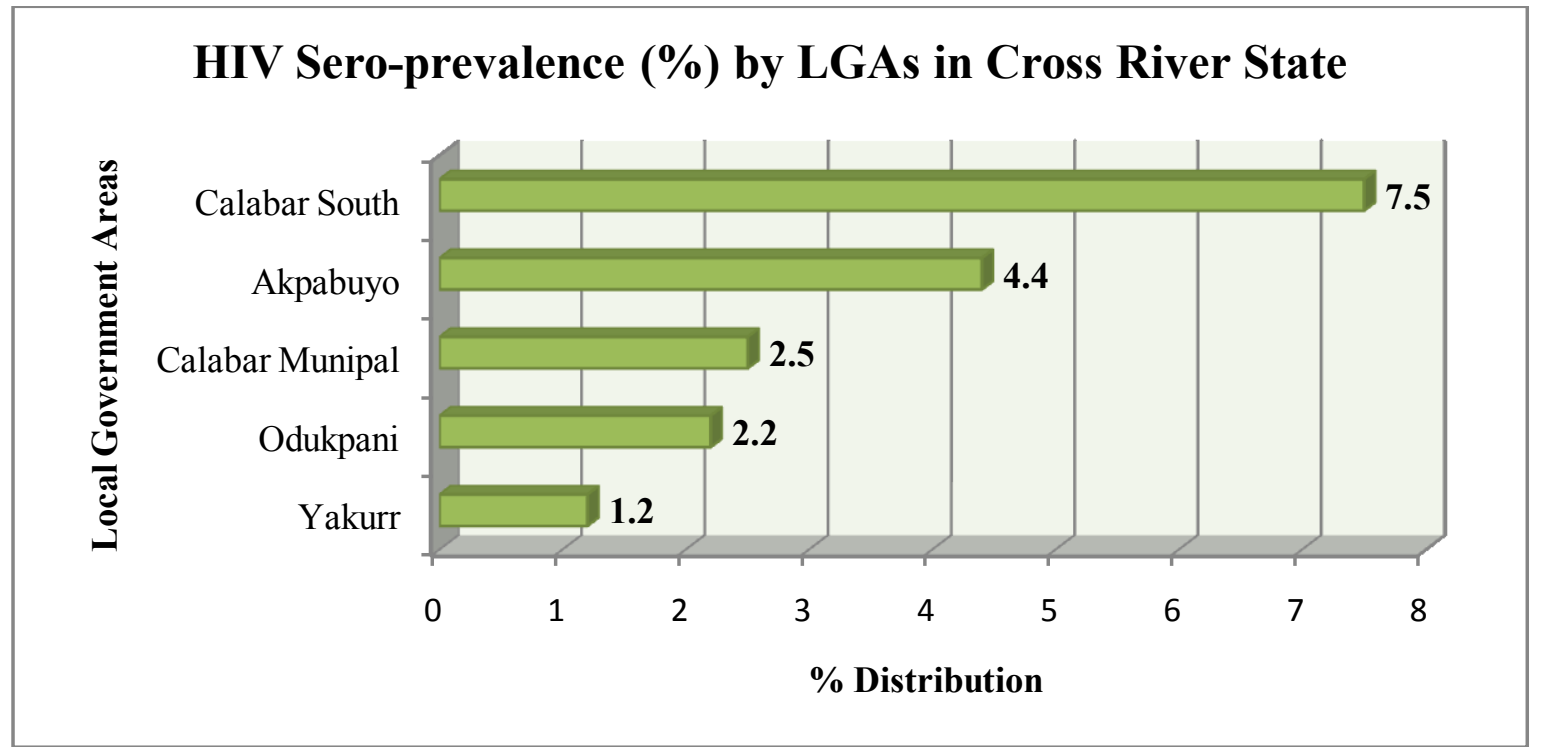

Figure 4: Distribution of the HIV Sero-prevalence among clients tested and counseled by LGAs in Cross River state.

\section{Discussion}

Studies have shown that HTC is a powerful tool in the battle against HIV/AIDS (Cardonick et al., 1998; Chadborn et al., 2004) ${ }^{[2][3]}$. High uptake of HTC translates to more people being aware of their status, more infected people having early access to treatment, support and care, reduction in transmission of HIV to children and other previously uninfected people and reduction in AIDS related deaths. It can even translate to positive behavioral change and reduction in stigmatization and discrimination.

The study revealed that about $48.5 \%$ and $54.2 \%$ of male and female clients respectively accessed HTC services in the study sites. From "fig." 1 above, it is reasonable to suggest that there wasa disproportionate distribution in the uptake of HTC services among the study clients and these varied from one LGA to the other.Research conducted in some other countries of Sub-Saharan Africa such as Kenya, Ghana and Uganda equally reported varying levels of uptake of HTC services among study participants in different study settings as well. In "fig." 2 above, it is possible to deduce that there has been a progressive increaseand varying degree of 
HTC uptake among female clients in three LGAs which include; Calabar South, Calabar Municipal and Akpabuyo as compared with male clients.

Reports from other national and regional studies conducted within the country corroborate the findings in this study. For example, the 2003 Nigerian Demographic and Health Survey (NDHS) reported an overall HTC uptake of three and six percent for men and women respectively, while the 2005 National HIV/AIDS and Reproductive Health Survey (NARHS) reported an overall uptake of 11 and $10 \%$ for men and women respectively (FMOH, 2010) $)^{[5]}$.

Lower levels of HTC uptake reported in this and other population based studies could be due to differences in the population studied (National Population Commission, 2004, 2009; Federal Ministry of Health Nigeria, 2010 $)^{[9][5]}$. Studies conducted among homogeneous segments of the population like pregnant women reflected a progressive increase in uptake of HTC among them (Oladokun et al., 2010) ${ }^{[12]}$. The higher uptake level can be explained by the Prevention of Mother-To-Child-Transmission (PMTCT) Programme commenced in ante-natal clinic settings across the country in 2003. This made it mandatory for all pregnant women accessing ante-natal care even in the most rural community setting to access HTC at the same time, unless they choose to opt out (FMOH, 2010) ${ }^{[5]}$.

Studies conducted among pregnant women attending ante-natal care in other countries of Sub-Saharan Africa, where PMTCT had been commenced also reported a similar increase in HTC uptake among them (Creek et al., 2007; Kasenga et al., 2009) ${ }^{[4]}{ }^{[6]}$. This implies that making HTC services readily available where they can be easily accessed, combined with continuous health education as obtained in PMTCT settings, can help to improve the uptake of HTC.

The proportion of clients that accessed HTC ranged increasingly from 7\% in Odukpani LGA to $40 \%$ in Akpabuyo LGA.Odukpani is predominantly a rural LGA having most of its ward located in the creeks while Akpabuyo Local Government Area which measures approximately 28.5 square kilometers is predominantly an agricultural area, and it is known as the Food Basket of Cross River State. Akpabuyo is rich in mineral deposits such as petroleum deposits, gold, limestone, sand and slat deposits to mention a few.Higher levels of HTC uptake in Akpabuyo is probably due to the industrialized nature of the LGA with residents having better access to health facilities. This finding in HTC uptake disparity has policy implications for the location of HTC centres. Presence of HTC centres in rural and semi-urban areas can encourage more people in such places to know their HIV status.

In "fig." 3 above, it is possible to suggest that the 5 LGAs have a generalized epidemic (i.e., HIV prevalence among the population $>1 \%$ ). In each of the 5 LGA, it is evident that HIV prevalence is higher among female clients as compared with male clients and this is in line with previous studies that HIV Sero-prevalence among young women aged 15-24 years is estimated to be three times higher than among men of the same age $(\mathrm{NACA}, 2011)^{[11]}$. This therefore suggests females as potential reservoirs for the HIV transmission in those communities and the need for tailored HIV program interventions.

"Fig." 4 above shows the trend analysis of the HIV Sero-prevalence in each of the 5 LGAs in Cross River state. HIV Sero-prevalence is higher in Calabar South LGA (7\%) with Yakurr LGA being the least $(1.2 \%)$. Yakurr is located in the central zone of Cross River and has a population of 38,000 in the 1991 census, while Calabar south which is predominantly urban, is located in the southern zone of Cross River and has a population of 191,630 in the 2006 census. Calabar south is known to be the venue of the largest tourist center in the country called 'Tinapa". The high rate of HIV Sero-prevalence in Calabar south can be attributed to the high population influx and possibly high risky sexual behaviors among the population. Recent study in Calabar South, Cross River suggests night parties, keeping bad company, indecent dressing and rape as risky lifestyles putting youths at risk of HIV infection. A HIV prevalence of 7.5\% in Calabar South suggests the presence of both generalized (i.e., HIV prevalence among the population $>1 \%$ ) and concentrated (i.e., HIV prevalence among a population sub-group $>5 \%$ ) epidemic. This finding therefore flags Calabar South LGA a suitable project site for key population interventions.

\section{Conclusion}

This result indicates that HIV Prevalence among women is disproportionately greater than the HIV Prevalence among men in Cross River state which appeared significant at the $95 \%$ confidence interval. From this study, the clients had poor uptake of HIV Testing and Counseling in some of the LGAs and uptake of HTC can be increased through the use of evidence based practices like; mobilization officers or community based volunteers.

Continuous media education and intensive social marketing of HTC with provision of more testing sites, especially in rural areas, along with scaling up of HIV testing and counseling services in routine medical and obstetric care should be done to improve the uptake of HTC.

The implementers of Health intervention should map appropriate strategies to evaluate Behavioral factors such as; Poor Self efficacy, Decision making skills, Condom negotiation skills, and High informal Non- 
transactional Sex which may be the predisposing drivers for the disproportionate burden of HIV Prevalence among men and women.

\section{References}

[1]. Boswell, D. and R. Baggaley, 2002. Voluntary counseling and Testing (VCT) and Young People: A Summary Overview. Family Health International, USA.

[2]. Cardonick, E., S. Daly, M. Dooley, K. Elles and N.S. Silverman, 1998. Determinants of ante-partum human Immunodeficiency virus testing in a non-medicaid obstetric population. Infect. Dis. Obstet. Gynecol., 6: 209-213.

[3]. Chadborn, T.R., C.A. McGarrigle, P.A. Waight and K.A. Fenton, 2004. On behalf of the HIVtesting Surveillance collaborative group. Sex.Transm. Infect 80: 145-150.

[4]. Creek, T.L., R. Ntumy and K. Seipone, 2007. Successful introduction of routine opt-out HIVtesting in antenatal Care in Botswana. J. Acquir. Immune.Defic.Syndr. 45: 102-107.

[5]. Federal Ministry of Health Nigeria, 2010. National HIV/AIDS and Reproductive Health Survey.Federal Ministry of Health Nigeria, Abuja, Nigeria.

[6]. Kasenga, F., P. Byass, M. Emmelin and A.K. Hurtig, 2009. The implications of policy changeson the uptake of a PMTCT programme in rural Malawi: First three years of experience. Glob. Health Action, 2: 1883, DOI: 10.3402/gha.v2i0.1883.

[7]. Kipp, W., G. Kabagambe and J. Konde-Lule, 2002. HIV counseling and testing in rural Uganda: Communities' attitudes and perceptions towards an HIV counseling and testing programme. AIDS Care, 14: 699-706.

[8]. National HIV Sentinel Survey, Nigeria, 2010

[9]. National Population Commission (NPC), 2004. Nigerian Demographic and Health Survey, 2003. National Population Commission (NPC) and ORC Macro, Calverton, MD., USA.

[10]. Retrievedfrom:http://www.measuredhs.com/pubs/pdf/GF5/nigeria2003generalfactsheet.pdf.

[11]. National Population Commission (NPC), 2007. Provisional Results of 2006 Population Census. Federal Government's Extraordinary Gazette, The Federal Government Printer, Lagos, Nigeria, 94(24).

[12]. Nigeria National Agency for the Control of AIDS. NationalHIV/AIDS Strategic Plan 2010 - 2015. Abuja Nigeria: Nigeria National Agency for the Control of AIDS, 2010.

[13]. Oladokun, R.E., O. Awolude, B.J. Brown, O. Adesina, A. Oladokun, et al., 2010. Service uptakeand performance of the Prevention of Mother-to-Child Transmission (PMTCT) programme in Ibadan, Nigeria. Afr. J. Med. Med. Sci., 39: 81-87.

[14]. Paul, S.M., E.M. Cadoff and E. Martin, 2004. Rapid diagnostic testing for HIV-clinicalimplications. BusinessBriefing. Clin.Virol. Infect. Dis., 100(9): 33.

[15]. Turner-Stokes, L., 2005. HIV Testing for Patients Attending General Medical Services: NationalGuidelines. Royal College of Physicians, London.

[16]. WHO, UNAIDS and UNICEF, 2010. Towards Universal Access: Scaling up Priority HIV/AIDSInterventionsin the Health Sector. WHO, Geneva, Switzerland.

[17]. UNAIDS, (2011) Report on the Global AIDS Epidemic 2011. UNAIDS, Geneva, Switzer land.

[18]. UNAIDS (2006) Report on the global AIDS epidemic Geneva, Switzerland: United Nations Joint Programme on AIDS.

[19]. UNAIDS (2008) Report on the global AIDS epidemic Geneva, Switzerland: United Nations Joint Programme on AIDS. 